\title{
PENGARUH LAYANAN BIMBINGAN KELOMPOK TEKNIK DISKUSI TERHADAP KOMUNIKASI INTERPERSONAL MAHASISWA ASAL MALAYSIA DI JURUSAN BK FIP UNIMED TAHUN AJARAN 2017 / 2018
}

\author{
Ali Usnan \\ Dra. Rahmulyani, M.Pd.,Kons \\ Program Studi Bimbingan dan Konseling \\ FIP Universitas Negeri Medan
}

\begin{abstract}
Abstrak
Penelitian ini bertujuan untuk mengetahui Pengaruh Layanan Bimbingan Kelompok Teknik Diskusi Terhadap Komunikasi Interpersonal Mahasiswa Asal Malaysia Di Jurusan BK FIP Unimed Tahun Ajaran 2017/2018. Subjek dalam penelitian ini adalah 7 orang mahasiswa asal Malaysia di Jurusan BK FIP UNIMED yang ditentukan dari hasil screening (penyaringan). Teknik pengumpulan data menggunakan angket, dan di analisis dengan menggunkan uji Wilcoxon. Hasil analisis data yang diperoleh dari uji wilcoxon ini adalah nilai $J_{\text {hitung }}=0$ dengan $\alpha=0,05$ dan $n=7, J_{\text {tabel }}=2$ dengan demikian $J_{\text {hitung }}<J_{\text {tabel }}(0<2)$. Artinya hipotesis ditolak. Hasil data pre-test di peroleh rata-rata 66 dan data post-test diperoleh rata-rata 96,1 artinya skor rata-rata mahasiswa asal Malaysia di Jurusan BK FIP UNIMED Tahun Ajaran 2017/2018 setelah mendapatkan layanan bimbingan kelompok teknik diskusi lebih tinggi. Perubahan peningkatan interval komunikasi interpersonal mahasiswa asal Malaysia di Jurusan BK FIP UNIMED Tahun Ajaran 2017/2018 setelah diberikan layanan bimbingan kelompok teknik diskusi diperoleh skorse besar 30.1 (45\%). Hal ini menunjukan ada pengaruh pemberian layanan bimbingan kelompok teknik diskusi terhadap kumunikasi interpersonal mahasiswa asal Malaysia di Jurusan BK FIP UNIMED Tahun Ajaran 2017/2018 sebesar 45 \%.Kata Kunci: Komunikasi Interpersonal, Bimbingan Kelompok Teknik Diskusi.
\end{abstract}

\section{PENDAHULUAN}

Komunikasi interpersonal merupakan salah satu keterampilan yang penting dimiliki dan dikuasai oleh manusia, pandangan terhadap komunikasi interpersonal sebagai keterampilan, melihat keterampilan komunikasi interpersonal sebagai proses yang diarahkan oleh tujuan komunikasi dan membutuhkan adanya koordinasi tertentu dengan orang lain yang terlibat dalam komunikasi interpersonal.

Komunikasi interpersonal tidak hanya dapat dilakukan secara individual namun juga dapat dilakukan secar kelompok (group communication) yang berarti komunikasi interpersonal yang berlangsung antara seorang komunikator dengan sekelompok orang yang jumlahnya lebih dari dua orang. Jadi apabila komunikasi interpersonal dilakukan oleh seseorang atau dua orang, itu termasuk juga komunikasi antarpribadi (komuniksi interpersonal).

Berdasarkan hasil studi pendahulu yang peneliti lakukan dengan menyebarkan angket yang berjumlah 40 pertanyaan pada tanggal 25 Mei 2017 kepada 18 orang mahasiswa asal Malaysia mendapatkan nilai rata-rata 88.7 dan dari hasil penghitungan 11 orang kategori 
rendah, 4 orang kategori sedang dan 3 orang kategori tinggi. Dari hasil tersebut dikatakan mahasiswa asal Malaysia kurang memiliki kemampuan komunikasi interpersonal. Dari hasil wawancara peneliti lakukan kepada beberapa mahasiswa asal Malaysia menunjukkan bahwa mereka mengalami kesulitan berkomunikasi interpersonal yang baik. Efek dari komunikasi interpersonal yang kurang baik ini menyebabkan sering terjadi kesalah pahaman pada saat berkomunikasi. Dengan demikian dapat mengakibatkan mahasiswa asal Malaysia tidak dapat bersosialisasi dengan baik di lingkungan perkuliahan dan lingkungan sosial mahasiswa psikologi pendidikan bimbingan di Unimed dengan baik. Sehingga menimbulkan kurangnya identitas diri mahasiswa asal Malaysia dan lain-lain.

Masalah yang timbul karena komunikasi interpersonal yang tidak baik perlu dibantu sebab akan menimbulkan dampak negatip baik terhadap diri sendiri maupun terhadap orang lain. Banyak cara yang dilakukan untuk memperbaiki cara komunikasi interpersonal yang tidak baik bagi mahasiswa asal Malaysia, namun salah satu cara yang dinilai efektip untuk memperbaiki komunikasi interpersonal yang tidak baik bagi mahasiswa asal Malaysia dalam hubungan interaksi antara mahasiswa dengan melakukan bimbingan kelompok menggunakan teknik diskusi.

Teknik layanan bimbingan kelompok ini sangat berguna bagi konselor sebagai sarana untuk memberikan materi dalam memperbaiki komunikasi interpersonal yang tidak baik pada mahasiswa asal Malaysia, sangat berguna bagi mahasiswa asal Malaysia untuk dapat melakukan komunikasi interpersonal yang baik dalam berintraksi di lingkungan sosialnya, baik di rumah, perkuliahan, maupun dilingkungan masyarakat.

Teknik layanan bimbingan ini, merupakan salah satu teknik bimbingan yang berusaha mambantu individu agar dapat mencapai perkembangan secara optimal sesuai dengan kemampuan, bakat, minat, serta nilai-nilai yang di anut dan dilaksanakan dalam situasi kelompok. Menurut Sudjana (2001:99 ) diskusi kelompok adalah pembicaraan melalui tatap muka yang direncanakan dua orang peserta didik atau lebih tentang pokok atau topik bahasan tertentu dan dipimpin oleh seseorang pemimpin kelompok. Teknik diskusi kelompok ini juga merupakan salah satu peroses bimbingan dimana mahasiswa akan mendapatkan suatu kesempatan untuk menyumbangkan pikiran masing-masing dalam memecahkan masalah bersama, dalam 
diskusi ini tertanam pula tanggung jawab dan harga diri.

Layanan bimbingan dan konseling dapat untuk meningkatkan komunikasi interpersonal mahasiswa salah satunya melalui bimbingan kelompok. Karena dengan bimbingan kelompok mahasiswa akan terbuka dalam menyampaikan pendapat dan mahasiswa akan terlatih untuk dapat menggunakan komunikasi interpersonal yang baik.

\section{KAJIAN PUSTAKA}

Menurut Rogers (dalam Cangara 2007:20) komunikasi adalah proses dimana suatu ide dialihkan dari sumber kepada satu penerima atau lebih dengan maksud untuk mengubah tingkah laku mereka.

Kita tidak dapat hidup sendiri untuk mempertahankan hidup. Kita perlu dan harus berkomunikasi dengan orang lain, untuk memenuhi kebutuhan biologis seperti makan dan minum, dan memenuhi kebutuhan psikologis, seperti sukses dan kebahagiaan, para psikologi berpendapat, kebutuhan utama kita sebagai manusia dan untuk menjadi manusia yang sehat secara rohaniah adalah kebutuhan akan hubungan sosial yang ramah, yang hanya bisa terpenuhi dengan membina hubungan baik dengan orang lain. Komunikasi akan sangat dibutuhkan untuk memperoleh dan memberi informasi yang akan sangat dibutuhkan untuk membujuk atau mempengaruhi orang lain, mempertimbangkan solusi alternatif atas masalah dan mengambil keputusan, dan tujuan- tujuan sosial secara hiburan.

Salah satu bentuk komunikasi informal yang perlu diwaspadai adalah desas-desus atau rumor. Desas-desus adalah pendapat yang tidak jelas tentang apa saja-orang, hal, peristiwa, kejadian. desas-desus tidak memiliki sumber berita yang berotoritas untuk menjamin kebenarannya. Berita desas-desus biasanya dengan "kata orang" "kabarnya" atau" menurut selentingan". Desas-desus menyebar melalui jaringan komunikasi yang digunakan orang untuk menyalurkan berita antara anggota-anggota kelompok nonformal. Jaringan ini dalam bahasa inggiris disebut grapevine.

Jaringan desas-desus dapat berupa : pertama, satu jalur (single strand) yang terdiri dari rantai panjang orang di mana satu orang meneruskan berita kepada orang berikutnya dalam rantai ini, dan orang ini meneruskan berita-berita kepada orang berikutnya lagi, dan seterusnya. Bentuk jaringan kedua adalah satu orang menyebarkan berita kepada banyak orang. Dalam bentuk jaringan yang ketiga, satu orang memberi berita kepada orang lain yang kemudian menyebarkan berita itu kepada satu atau dua orang. Satu 
dan dua orang itu pada gilirannya menyampaikan kepada satu atau dua orang yang lain. Akhirnya, bentuk jaringan desas-desus keempat, yaitu satu orang menyampaikan berita kepada sekelompok orang, dan masing-masing anggota kelompok itu kemudian menyalurkan kepada kelompok-kelompok lain.

Dalam semua bentuk jaringan desasdesus itu selalu ada orang yang berfungsi sebagai penghubung antara orang-orang yang sudah menerima berita dan orang lain yang belum menerima berita. Karena berfungsi sebagai penghubung,orang itu dalam bahasa inggiris disebut liaisan person. Dalam menyampaikan berita, penghubung bersikap selektif, ada orang yang diberitahu dan ada orang yang dilampaui. Ini bukan karena tidak percaya, tetapi karena penghubung tahu siapa yang dianggap pantas diberitahu atau tidak.

Umpan balik (feed back) merupakan tanggapan penerima terhadap pesan yang di terima dari pengirim. umpan balik dapat berupa tanggapan, verbal, maupun nonverbal.

Dipandang dari efektivitas komunikasi dan akibat komunikasi pada penerima, umpan balik dapat negatif dan positif. Umpan bali negatif adalah umpan balik yang menunjukkan bahwa penerima pesan tidak dapat menerima dengan biak pesan yang diterimanya. Umpan balik negatif dapat benar, tetapi juga dapat salah. Benar jika isi atau cara penyampaian pesan dilakukan secara benar, serta penafsiran dan penerjemahan penerima pesan juga benar. salah jika isi dan cara penyampian pesan dilakukan secara benar, tetapi penapsiran dan penerjemahan penerima pesan salah. Umpan balik negatif dapat dijadikan bahan pertimbangan bagi pengirim pesan untuk memperbaiki isi dan cara penyampian pesan, atau membatalkan pesan sama sekali.

Umpan balik positif, bila tanggapan penerima menunjukan kesedihan untuk menerima dan mengerti pesan dengan baik serta memberi tanggapan sebagaimana diinginkan oleh pengirim. Umpan balik positif membuat komunikasi bisa berlanjut. Urusan ditangani, dan hubungan antara pengirim dan penerima tetap atau bertambah baik. Baru sesudah umpan balik diterima oleh pengirim itulah komunikasi secara penuh terjadi.

Dalam komunikasi penuh secara bergantian peran penerima pesan berubah menjadi pengirim pesan, dan pengirim pesan berubah menjadi penerima pesan. Akibat pesan yang disampaikan, saluran yang digunakan serta situasi komunikasi ikut berubah-ubah pula. Komunikasi 
merupakan proses yang dinamis dan mendatangkan dampak baik pengirim dan penerima. Dampak itu dapat fisik, seperti kehangatan pada waktu berjabat tangan, emosional, seperti waktu hati menjadi gembira atau susah, kognitif seperti bertambahnya pengetahuan karena menerima informsi baru, atau gabungan dampak-dampak itu,

Bimbingan kelompok merupakan kegiatan yang memberikan kesempatan bagi anggotanya untuk mengubah penerimaan diri terhadap orang lain, memberikan ide, perasaan, dukungan bantuan alternatif pemecahan masalah dan mengambil keputusan yang tepat, dapat berlatih tentang perilaku baru dan bertanggung jawab atas pilihan yang ditentukan sendiri. setiap individu tidak dapat hidup dengan sendirinya, ia secara kodrat harus hidup bersama dengan individu lainnya dalam masyarakat cenderung memiliki bayak masalah yang timbul, akibat perbedaan diantara individu yang bayak ini, baik pemikiran, perasaan, kebutuhan keinginannya, sifatsifatnya, aspirasi, dan lain sebagainya.

Layanan bimbingan kelompok teknik diskusi yang selama ini dilaksanakan di perkuliahan merupakan layanan bimbingan yang memungkinkan sejumlah secara bersama-sama membahas berbagi topik yang saat ini sering terjadi, dan salah satunya adalah komunikasi interpersonal yang kurang baik di dalam lingkungan sosialnya, mahasiswa mengetahui faktorfaktor Yang mempengaruhi terjadinya komunikasi interpersonal yang tidah baik, dampak yang timbil dari komunikasi interpersonal yang kurang baik, serta kiatkiat dalam memperbaiki komunikasi interpersonal yang tidak baik pada mahasiswa asal malaysia di universitas.

Dengan adanya bimbingan kelompok teknik diskusi ini maka komunikasi interpersonal mahasiswa asal malaysia yang kurang baik dapat diperbaiki melalui dinamika kelompok. kemudia bersamasama anggota kelompok mencari solusi untuk mengatasi masalah tersebut. kemudian juga dapat ditingkatkan dalam bimbingan kelompok teknik diskusi.

\section{METODE PENELITIAN}

Jenis penelitian ini adalah eksperimen semu (quasi eksperimen) yaitu peneliti mengadakan penelitian langsung ke objek yang ingin diteliti (mahasiswa asal malaysia ) untuk memperoleh data-data yang dibutuhkan dengan memberikan angket atau pertanyaan kepada mahasiswa asal malaysia yang dijadikan subjek penelitian, dengan memberikan perlakuan atau tindakan kepada sekelompok orang atau subjek penelitian dengan pendekatan kumulatif. 
Variabel penelitian ini terdiri dari variabel bebas dan variabel terikat. Variabel bebas (Variabel $\mathrm{X}$ ) adalah bimbingan kelompok teknik diskusi dan variabel terikat (variabel $\mathrm{Y}$ ) adalah peningkatan komunikasi interpersonal.

Instrumen pengumpulan data yang digunakan untuk mengetahui kumunikasi interpersonal mahasiswa asal Malaysia adalah dengan angket tertutup. Dimana jawaban terhadap item soal telah disediakan responden hanya tinggal memilih jawaban yang sesuai dengan dirinya sendiri.

Dalam memberikan jawaban mahasiswa asal Malaysia hanya memberi tanda $(\sqrt{ })$ pada kolom atau tempat yang sudah disediakan. Angket ini sebelum diberikan pada responden akan difaliditasi dan akan diuji coba, ini akan diberikan pada mahasiswa lain yang bukan responden namun memiliki karakteristik yang hampir sama dengan responden.

Untuk mengumpulkan data dalam penelitian ini adalah skala yang di susun oleh peneliti. Skala yang disusun bersifat skala original yang berpedoman pada skala likert. Pernyataan terdiri dari pernyataan positif dan negatif. Setiap pernyataan memiliki 4 alternatif jawaban yaitu Sangat Setuju (SS), setuju (S), Kurang setuju (KS), Sangat tidak setuju (STS).
Untuk menguji hipotesis diatas dengan taraf nyata $\alpha=0,05$, dibandingkan $\mathbf{J}$ diatas dengan $\mathbf{J}$ yang diperoleh dari tabel uji Wilcoxon. Jika J dari perhitungan lebih kecil atau sama dengan $\mathrm{J}$ dari daftar uji Wilcoxon, maka hipotesis ditolak dan sebaliknya, apabila $\mathbf{J}$ dari perhitungan lebih besar dari daftar tabel uji Wilcoxon maka hipotesis diterima.

Penelitian ini dilakukan di Universitas Negeri Medan Fakultas Ilmu Pendidikan Jurusan Psikologi pendidikan dan Bimbingan yang berlokasi di Jalan William Iskandar pasar V, Medan Estate. Kecamatan Percut Sei Tuan. Kabupaten Deli Serdang.

\section{HASIL DAN PEMBAHASAN}

Data dalam penelitian ini diperoleh dengan melakukan pengukuran terhadap komunikasi interpersonal mahsiswa malaysia dengan pemberian angket sebelum melaksanakan layanan bimbingan kelompok teknik diskusi (pretest) dan setelah melaksanakan layanan bimbingan kelompok teknik diskusi (posttest). Selanjutnya data-data ini diolah dengan tahapan mulai dari deskripsi data, pengujian persyaratan analisis, dan pengujian hipotesis.

Subjek penelitian adalah mahasiwa asal Malaysia yang berjumlah 7 orang mahasiswa. Pengisian angket yang sudah diuji secara valid atau sahih yang 
berjumlah 31 item disebarkan ke mahasiwa asal malaysia yang berjumlah 18 mahasiswa untuk mengambil sampel sebanyak 7 orang yang terdiri dari 5 mahasiswa kategori rendah. 1 mahasiswa kategori sedang dan 1 mahasiswa kategori tinggi. Alasan peneliti memilih sampel sebanyak 7 orang adalah karena keterbatasan waktu, dana, dan tenaga peneliti serta menjamin keefektifan dalam melaksanakan bimbingan kelompok teknik diskusi.

Pengujian hipotesis dilakukan dengan perhitungan uji jenjang bertanda wilcoxon pada uji jumlah jenjang wilcoxon diperoleh hasil perhitungan jumlah jenjang bertanda positif $=25$ dan jumlah jenjang bertanda negatif $=0$. Jadi, nilai $\mathrm{J}=$ 0 yaitu jumlah jenjang yang lebih kecil.

Hipotesis ditolak apabila $\mathrm{Z}_{\text {tabel }}>\mathrm{Z}_{\text {hitung. }}$.Karena nilai $\mathrm{Z}_{\text {tabel }}$ yaitu 1,645 dan itu lebih besar dari nilai $Z_{\text {hitung }}$ adalah -2,366. Dengan demikian, Hipotesis ditolak yang artinya ada perbedaan antara sebelum dan sesudah diberi bimbingan kelompok teknik diskusi dan Ha diterima yang artinya bimbingan kelompok teknik diskusi yang diberikan memang memberikan efek, sehingga dapat disimpulkan bahwa "Ada pengaruh yang signifikan antara layanan bimbingan kelompok dengan teknik diskusi terhadap peningkatan komunikasi interpersonal mahasiswa asal Malaysia Di Jurusan BK FIP Unimed Tahun Ajaran 2017/2018”. atau Hipotesis dapat diterima.

Berdasarkan uraian di atas, dapat diketahui bahwa teknik diskusi dapat digunakan untuk mahasiswa asal Malaysia yang memiliki tingkat komunikasi interpersonal yang rendah. Hal ini juga sesuai pendapat Diskusi kelompok adalah teknik bimbingan kelompok yang dilaksanakan dengan maksud agar para mahasiswa asal Malaysia anggota kelompok dapat kesempatan untuk memecahkan masalah bersama-sama. Setiap mahasiswa asal malaysia mendapatkan kesempatan untuk menyumbangkan fikirannya. dalam memecahkan suatu masalah.

Diskusi kelompok adalah suatu pertemuan dua orang atau lebih yang ditunjuk pemikiran, pengalaman pendapat dan biasanya menghasikan keputusan bersam sukardi (2008 :220) sehingga dapat disimpulkan bahwa pemberian teknik diskusi dalam bentuk bimbingan kelompok dapat melatih ketrampilan dalam mengemukakan pendapat, melatih keberanian untuk mengungkapkan pendapat didepan orang banyak, dan melatih ketrampilan komunikasi interpersonal dalam bergaul

Jika mahasiswa ini terus memiliki komunikasi interpersonal yang rendah 
maka di khawatirkan dapat berdampak negatif terhadap diri nya salah satunya adalah kegiatan akademik yang sedang ia jalankan saat ini dapat tertunda dan terbengkalai.

Sebelum dilaksanakan layanan bimbingan kelompok teknik diskusi tingkat komunikasi interpersonal mahasiswa asal Malaysia di Jurusan BK FIP UNIMED rata -rata 66. Hal ini dibuktikan dari hasil angket dimana skor nilai mahasiswa Asal Malaysia di Jurusan BK FIP menunjukan tingkat komunikasi interpersonal sangat rendah. Dalam hal ini peneliti menggunakan layanan bimbingan kelompok teknik diskusi untuk mengatasi permasalahan tersebut. seperti yang kita ketahui bahwa layanan bimbingan kelompok adalah adalah layanan bimbingan dan konseling yang memungkinkan individu secara bersamasama, melalui dinamika kelompok memperoleh berbagai bahan dari narasumber tertentu terutama dari konselor dan atau membahas secara bersama-sama pokok bahasan tertentu guna untuk menunjang pemahaman dan kehidupan sehari-hari dan untuk perkembangan dirinya, baik sebagai individu maupun sebagai mahasiswa dan untuk pertimbangan dalam mengambil keputusan atau tindakan (Siti Hartina, 2009 : 104).
Dalam bimbingan kelompok terdapat berbagai teknik yang dapat digunakan salah satu nya adalah teknik diskusi dengan teknik ini peneliti ingin menggunakan dinamika dan juga peran kelompok dalam mengatasi komunikasi interpesonal. Setelah diberikan layanan bimbingan kelompok teknik diskusi terhadap komunikasi interpersonal mahasiswa asal Malaysia di Jurusan BK FIP UNIMED Tahun Ajaran 2017/2018 terdapat peningkatan komunikasi interpersonal sebesar $45 \%$.

Setiap rumusan masalah yang peneliti buat juga dialami oleh masing -masing mahasiswa asal Malaysia dan mereka juga dapat mengatasinya setelah diberikan layanan bimbingan kelompok teknik diskusi. Hal ini dibuktikan dengan hasil data yang di peroleh.nKomunikasi interpersonal $\mathrm{SH}$ sebelum pemberian layanan (pre-test) sebesar 67 dengan kategori sedang, dan komunikais interpersonal setelah pemberian layanan (post-test) sebesar 98 dengan kategori tinggi, dengan demikian SH mengalami peningkatan sebesar 31 dengan persentase sebesar $46 \%$. Komunikasi interpersonal AIN sebelum pemberian layanan (pretest) sebesar 99 dengan kategori tinggi, dan komunikasi interpersonal setelah pemberian layanan (post-test )sebesar 108 dengan kategori tinggi, dengan demikian 
AIN mengalami peningkatan komunikasi sangat sedikit 9 dengan persentase sebesar 9\% karena AIN mengalami masalah dalam penyesuaian bahasa dengan ini di perlukan bimbingan khusus kepada AIN agar dapat meningkatkan komunikasi interpersonal. Komunikasi interpersonal AJ sebelum pemberian layanan (pre-test) sebesar 60 dengan kategori rendah, dan komunikasi interpersonal setelah pemberian layanan (post-test) sebesar 97 dengan kategori tinggi, dengan demikian AJ mengalami peingkatan komunikasi sebesar 37 dengan persentase sebesar 62\%. Komunikasi interpersonal NUR sebelum pemberian layanan (pre-test) sebesar 59 dengan kategori rendah, dan komunikasi interpersonal setelah pemberian layanan (post-test)sebesar 96 dengan kategori tinggi, dengan demikian NUR mengalami peningkatan komunikasi sebesar 37 dengan persentase sebesar 62\%. Komunikasi interpersonal M.F sebelum pemberian layanan (pre-test) sebesar 60 dengan kategori rendah, dan komunikasi interpersonal setelah pemberian layanan (post-test) sebesar 96 dengan kategori tinggi, dengan demikian M.F mengalami peningkatan sebesar 36 dengan persentase penurunan sebesar 60\%. Komunikasi interpersonal SY sebelum pemberian layanan (pre-test) sebesar 59 dengan kategori rendah, dan komunikasi interpersonal setelah pemberian layanan (post-test) sebesar 98 dengan kategori tinggi, dengan demikian SY mengalami peningkatan sebesar 39 dengan persentase penurunan sebesar $66 \%$.

Komunikasi interpersonal MS sebelum pemberian layanan (pre-test) sebesar 58 dengan kategori rendah, dan komunikasi interpersonal setelah pemberian layanan (post-test) sebesar 80 dengan kategori sedang, dengan demikian MS mengalami peningkatan komunikasi interpersonal sebesar 22 dengan persentase penurunan sebesar $37 \%$.

Berdasarkan dari uraian diatas dapat dilihat bahwa ada peningkatan komunikasi interpersonal terhadap 7 mahasiswa asal Malaysia di Jurusan BK FIP UNIMED Tahun Ajaran 2017/2018 sebelum dan sesudah pemberian layanan bimbingan kelompok teknik diskusi. Sebelum pemberian layanan bimbingan kelompok teknik diskusi, rata-rata skor 7 mahasiswa asal Malaysia di Jurusan BK FIP UNIMED Tahun Ajaran 2017/2018 adalah 66, dan setelah pemberian layanan bimbingan kelompok teknik diskusi, ratarata skor 7 mahasiswa asal Malaysia di Jurusan BK FIP UNIMED Tahun Ajaran 2017/2018 adalah 96.1 dengan demikian ada peningkatan kumunikasi interpersonal 7 mahasiswa asal Malaysia di Jurusan BK 
FIP UNIMED Tahun Ajaran 2017/2018 sebesar $45 \%$ dengan selisih skor sebesar 30.1 .

Dengan demikian terbukti pemberian layanan bimbingan kelompok teknik diskusi yang di kemukakan Menurut sudjana (2001 :99 ) terapi kelompok teknik diskusi pada dasarnya merupakan pembicaraan melalui tatap muka yang direncanakan dua orang peserta atau lebih tentang pokok atau topik bahasan tertentu dan dipimpin oleh seseorang pemimpin kelompok.

Dalam penelitian ini tujuan yang ingin dicapai oleh peneliti adalah adanya pengaruh positif pemberian layanan bimbingan kelompok teknik diskusi terhadap kumunikasi interpersonal mahasiswa asal Malaysia di Jurusan BK FIP UNIMED Tahun Ajaran 2017/2018. Dengan adanya penelitian ini mahasiswa asal Malaysia di harapkan mampu mengembangkan potensinya dalam memecahkan masalah dan mencari solusi dari komunikasi interpersonal yang di alami sehingga nantinya dapat mandiri dan percaya diri dalam menghadapi masalah yang sama di kemudian hari.

Berdasarkan hasil penelitian diperoleh bahwa layanan bimbingan kelompok dengan teknik diskusi berpengaruh terhadap peningkatan komunikasi interpersonal mahasiswa asal Malaysia Di Jurusan BK FIP Unimed Tahun Ajaran 2017/2018 .Hal itu dibuktikan dengan hasil perhitungan uji hipotesis diperoleh koefisien $\mathrm{J}$ sebesar 0 . Dari tabel nilai kritis $\mathbf{J}$ untuk uji jenjang bertanda wilcoxon untuk $\mathrm{n}=7, \alpha=0,05$ pengujian dua arah $\mathrm{J}_{0,05}=2$. Oleh karena $\mathbf{J}_{0,05}(2)>\mathbf{J}(0)$ maka hipotesis ditolak. Dari data statistik tersebut maka hipotesis diterima yang artinya terdapat pengaruh penyelenggaraan bimbingan kelompok dengan teknik diskusi terhadap peningkatan komunikasi interpersonal mahasiswa asal Malaysia Di Jurusan BK FIP Unimed Tahun Ajaran 2017/2018.

\section{PENUTUP}

\section{Kesimpulan}

Dari hasil penelitian dapat disimpulkan bahwa ada pengaruh layanan bimbingan kelompok dengan teknik diskusi terhadap komunikasi interpersonal mahasiswa asal Malaysia Di Jurusan BK FIP Unimed Tahun Ajaran 2017/2018 hal ini di ketahui dari hasil pre-test mempunyai rata-rata $(\mathrm{M})=66$ dan standar deviasi $(\mathrm{SD})=14,23$ sedangkan post-test rata-rata $(\mathrm{M})=96,1$ dan standar deviasi $(\mathrm{SD})=10,9$ dan hasil perhitungan uji hipotesis diperoleh data $\mathrm{J}_{\text {tabel }}$ lebih besar dari $\mathbf{J}_{\text {hitung }}(2>0)$. Karena $\mathbf{J}_{\text {tabel }}$ lebih besar dari $\mathrm{J}_{\text {hitung, maka hipotesis ditolak }}$ hal ini diperkuat dengan persamaan rumus 
Z. karena nilai $Z_{\text {tabel }}$ yaitu $-1,645$ dan itu lebih bedar dari nilai $Z_{\text {hitung }}$ adalah -2.366 , maka hipotesi ditolak artinya terdapat perbedaan antara sebelum dan setelah diberi perlakuan sehingga, komunikasi interpersonal mahasiswa setelah mengikuti bimbingan kelompok dengan teknik diskusi lebih tinggi daripada sebelum mengikuti bimbingan kelompok dengan teknik diskusi.

\section{Saran}

Berdasarkan kesimpulan diatas, maka sebagai saran yang bisa dikemukakan penulis dalam penelitian ini adalah:

Adapun saran yang dikemukakan penelitian adalah :

1. Diharapkan bagi mahasiswa penelitian ini dapat membantu mahasiswa untuk mengatasi masalah komunikasi interpersonal yang ia alami.

2. Diharapkan bagi dosen pembimbing akademik penelitian ini dapat bermanfaat dalam menindak lanjuti kegiatan layanan bimbingan kelompok khususnya kegiatan bimbingan kelompok untuk membantu mahasiswa asal Malaysia lebih terbuka dalam mengungkapkan permasalahan dan dapat mengatasi masalah komunikasi interpersonal.

3. Diharapkan bagi peneliti lainnya dapat melanjutkan penelitian komunikasi interpersonal mahasiswa asal Malaysia untuk meningkatkan komunikasi interpersonal.

4. Diharapkan bagi peneliti lainnya dapat dijadikan bahan masukan dan sumber refrensi dalam penelitian di bidang yang sama terutama untuk menumbuh kembangkan kemampuan dan keterampilan meneliti serta menulis.

5. Diharapkan bagi konselor penelitian ini dapat bermanfaat dalam menindak lanjuti kegiatan layanan bimbingan kelompok. Kegiatan lanjutan berupa konseling kelompok atau konseling individu agar mahasiswa asal Malaysia dapat lebih terbuka dalam mengungkapkan permasalahan dan dapat mengatasi masalah komunikasi interpersonal.

\section{DAFTAR PUSTAKA}

Amti, Erman dan Prayitno. 2004. Dasar-dasar Bimbingan Kelompok. bandung : PT Rapika Aditama.

Arikunto.1997. Prosedur Penelitian. Jakarta: Bina Aksara

Arikunto, Suharsimi. 2010. Prosedur Penelitian Suatu Kendekatan Praktik. Jakarta: Rineka Cipta.

AW, Suranto. 2010. Komunkasi Sosial Budaya, edisi pertama. Yogyakarta: Garaha ilmu.

AW,Suranto. 2011. Komunikasi Interpersonal. Yogyakarta: Graha Ilmu. 
Cangara. 2007. Pengantar ilmu Pendidikan. jakarta: PT Raja grapindo persada.

Hadjana, Agus M. 2003. Komunikasi Intrapersonal dan Interpersonal. yogyakarta: Kanisius.

Hidayat, Dasrun. 2012. Komunikasi Antar Pribadi dan Medianya (fakta Penelitian Fenomenologi Orang Tua Karir dan Anak Remaja. Yogyakarta: Graha ilmu.

Kusumaningsih, Marta. Dan Mulyana Olievia. 2013. Hubungan Antara Komunikasi Interpersonal dengan Penyesuaian Diri Pada Siswa Remaja.

Liliweri, Alo. 2011. Komunikasi: Serba Ada Serba Makna. Jakarta: kencaan

Putra, Nanda Fitriyan. 2013. Peranan komunikasi interpersonal orang tua dan anak dalam mencegah perilaku seks pranikah di sma negeri 3 samarinda kelas XII.

Santoso, Edi dan Setiansah, Mite. 2012. Teori komunikasi. yogyakarta: Graha Ilmu.

Sudjana. 2001. Metode dan Teknik Pembelajaran Partisipatif. Bandung : Falah produktion.

Sukardi, dkk. 2008. Pengantar Pelaksanaan Ilmu Program Kimbingan dan Konseling Disekolah. Jakarta : Pustaka Belajar.

Surip, Muhammad. 2013. Komunuikasi Antar Pribadi (persspektif Teoritis dan Aplikasi). Medan: unimed press.
Prayitno. 1995. Layanan Bimbingan dan Konseling Kelompok (Dasar dan Profil). jakarta: Ghalia Indonesia. 